\title{
Pericarditis as a Rare Complication of Severe Leptospirosis
}

Edmond Puca*, Gentian Stroni, Elda Qyra, Zhenisa Hysenaj, Liridon Zguri and Arben Pilaca

University Hospital Center, Tirana, Albania

"Corresponding author: Edmond Puca, University Hospital Center, Tirana, Albania, Tel: 0672058624; E-mail: edmond_puca@yahoo.com

Received date: July 03, 2015, Accepted date: August 01, 2015, Published date: August 03, 2015

Copyright: (c) 2015 Puca E, et al. This is an open-access article distributed under the terms of the Creative Commons Attribution License, which permits unrestricted use, distribution and reproduction in any medium, provided the original author and source are credited.

\begin{abstract}
Leptospirosis is a disease with a large geographical spreading. The clinical picture varies from undiagnosed, flulike syndrome to multiorgan involvement forms. Involvement of pericardium during leptospirosis is a rare event but not unknown.
\end{abstract}

Objective: Our aim is to describe a severe case of leptospirosis (Weil's diseases) with prominent liver involvement, complicated with exudative pericarditis.

Materials and Methods: A male patient, working as a mechanic, presents with fever, conjunctival suffusion, jaundice, pronounced myalgia and anuria for more than two days. Based on the clinical evidence, laboratory results showing multiorgan involvement and the epidemiological data, the patient was suspected for leptospirosis.

Results: Referring to the above mentioned data, the patient was serologically tested with ELISA for leptospirosis, which resulted positive for IgM and IgG in two blood samples.

Conclusion: Severe clinical presentations of leptospirosis are not rare and cardiac involvements are not to, but remain underreported in most of the cases. Through this case report, we want to share our experience with our colleague and at the same time we want to bring into attention the rare complications of leptospirosis, such as pericarditis in our case.

Keywords: Leptospirosis; Weil's disease; Acute liver failure; Pericarditis

\section{Introduction}

Leptospirosis is a zoonosis widespread in the world, especially in the tropical countries, which may lead to multi-organ involvement during its course. Leptospires are spirochetes belonging to the order Spirochaetales and the family Leptospiraceae [1-3]. In general there was a seasonal distribution of the disease, but with recent climate's changes, this disease can be seen throughout the whole year. Leptospirosis typically has two clinical forms: anicteric and icterohaemorrhagic and the disease follow to phases: septicemic and immune. Fever, nausea and vomiting, headache, myalgia, diaphoresis, conjunctival suffusion, anorexia, and malaise are usually present in the acute phase or septicemic phase of leptospirosis. The severe forms with hepatorenal involvement are also known as Weil's disease in honor of Adolf Weil who was the first to describe it [1]. The pathophysiology of the diseases is closely related to the vasculitis that leptospira causes. Usually the diseases has a good clinical outcome, with $90 \%$ of the cases presenting as anicteric or subclinical forms and only $10 \%$ resulting into aggressive form involving many organs. The most affected organs are the kidney and liver, although being a systemic disease no organ is spared. Our aims are to present a severe case of leptospirosis with multiple organ failure (MOF) and complicated with pericarditis. This article discusses a case of Weil's disease in a patient who presents to the emergency department with signs of liver and kidney failure.

\section{Case Presentation}

Our case is a 41 year-old male, immunocompetent, who worked as a mechanic in his private workshop in the suburbs of the city. The patient was initially seen in the emergency room of the Infectious Diseases Department, "Mother Teresa" University Hospital Center, Tirana, Albania. On first presentation the patient appeared flushed, a varicelliform rash over the face and neck, and jaundiced. He refers fever, headache, severe fatigue, diffuse musculoskeletal tenderness, nausea, vomiting for more than two days. The patient was alert and oriented, furthermore fever of $38.7^{\circ} \mathrm{C}$, conjunctival suffusion, arterial blood pressure $60 / 30 \mathrm{mmHg}$ and heart rate 135 beats per minute were evident on first physical examination. The lung sounds were reduced on the right lower third, with respiratory rate: 22-24 rates per minute. Symptoms had started 3 days ago with high fever, headache and nausea. For the last two days there had been a decrease in urinary output. His past medical history was unremarkable. He not suffered from any diseases. Referring to the epidemiological data (mechanic, worked in the suburbs of the city, in an endemic area for leptospirosis) and the clinical picture he was suspected suffering from leptospirosis. He was immediately started on IV fluid due to his hemodynamic instability. His laboratory results were as follows: white blood cell count (WBC): $19300 / \mathrm{mm}^{3}$, platelet count: $38000 / \mathrm{mm}^{3}$, total bilirubin $4.7 \mathrm{mg} / \mathrm{dl}$, urea $52.8 \mathrm{mg} / \mathrm{dl}$, creatinine $3.65 \mathrm{mg} / \mathrm{dl}$, aspartate aminotransferase (SGOT) $6480 \mathrm{U} / \mathrm{L}$, alanine aminotransferase (SGPT) $6480 \mathrm{U} / \mathrm{L}$, creatine phosphokinase (CPK) $2870 \mathrm{U} / \mathrm{L}$. 
Citation: Edmond P, Gentian S, Elda Q, Zhenisa H, Liridon Z, et al. (2015) Pericarditis as a Rare Complication of Severe Leptospirosis. Trop Med Surg 3: 193. doi:10.4172/2329-9088.1000193

Page 2 of 4

\begin{tabular}{|c|c|c|c|c|c|c|c|c|c|}
\hline Day & 0 & 1 & 2 & 3 & 4 & 5 & 7 & 10 & 14 \\
\hline WBC $\left(3.5-10.0 \times 10^{3} / \mathrm{mm}^{3}\right)$ & 19.3 & 16.8 & 11.2 & 9.1 & 8.0 & 10.2 & 11.35 & 7.8 & 7.2 \\
\hline $\begin{array}{l}\text { Neutrophils } \\
(43-76 \%)\end{array}$ & 89.9 & 91.2 & 85.1 & 87.2 & 88.1 & 78.8 & 76.7 & 68.7 & 63.4 \\
\hline $\begin{array}{l}\text { Platelet count } \\
\left(150-390 \times 10^{3} / \mathrm{mm}^{3}\right)\end{array}$ & 0.38 & 0.624 & 0.98 & 1.58 & 1.87 & 2.56 & 3.24 & 3.3 & 3.65 \\
\hline $\begin{array}{l}\text { Urea } \\
\text { (10- } 43 \mathrm{mg} / \mathrm{dL})\end{array}$ & 52.8 & 69.8 & 134 & 151 & 169.2 & 145.1 & 89.4 & 50.2 & 43.2 \\
\hline $\begin{array}{l}\text { Creatinemia } \\
(0,6-1,3 \mathrm{mg} / \mathrm{dL})\end{array}$ & 3.65 & 4.98 & 6.2 & 8.4 & 5.81 & 4.72 & 3.06 & 1.39 & 1.17 \\
\hline $\begin{array}{l}\text { ALT (SGPT) } \\
(0-45 \mathrm{mg} / \mathrm{dL})\end{array}$ & 6330 & 4700 & 1989 & 928 & 1102 & 859 & 622 & 198 & 110 \\
\hline $\begin{array}{l}\text { AST (SGOT) } \\
(0-35 \mathrm{mg} / \mathrm{dL})\end{array}$ & 6480 & 4680 & 1740 & 980 & 750 & 650 & 345 & 165 & 84 \\
\hline $\begin{array}{l}\text { CPK } \\
\text { (0- } 171 \text { UI/L) }\end{array}$ & 4870 & 4150 & 3700 & 2240 & 1560 & 1060 & 720 & 380 & 250 \\
\hline $\begin{array}{l}\text { Total Bilirubin } \\
(0,3-1,2 \mathrm{mg} / \mathrm{dL})\end{array}$ & 4.7 & 4.5 & 6.2 & 9.4 & 10.7 & 10.8 & 7.1 & 4.2 & 2.75 \\
\hline $\begin{array}{l}\text { Protrombine Time } \\
(11,8-15,1 \mathrm{~s})\end{array}$ & 12 & 17.6 & 30.2 & 45.7 & 62.7 & 63.8 & 68.3 & 75.2 & 72.3 \\
\hline $\begin{array}{l}\text { INR } \\
(0,720-1,200 \%)\end{array}$ & 8.4 & 4.27 & 2.3 & 1.91 & 1.4 & 1.28 & 1.21 & 1.0 & 1.01 \\
\hline
\end{tabular}

Table 1: The patient follow up with hemogram, liver and renal function.

Tests for hepatitis $\mathrm{C}$ virus antibody (anti-HCV), hepatitis B (HBsAg, HBeAg, anti-HBc IgM and IgG and anti-HBs), hepatitis A antibody and hemorrhagic fever were negative. No signs of bleeding were present. Fluid resuscitation is initiated with $0.9 \%$ saline, in combination with glucose $5 \%$. He receives a total of $1000 \mathrm{~mL}$ of fluid by the time that the laboratory results became available. Chest $\mathrm{x}$-ray revealed left basal pneumonia associated with minimal pleural effusion of the ipsilateral side. Treatment was initiated with Ampicillin $6 \mathrm{~g} /$ day. The clinical course of the patient was satisfactory. There was a marked improvement in diuresis within the first 20 hours of hospitalization, after his BP increased to $100 / 60 \mathrm{mmHg}$ and was started on diuretics. Positive results of specific serologic tests for leptospirosis IgM and IgG ELISA were found in two blood samples examination in the second and third week of the disease (Figure 1).

The patient was followed by a good progression, because liver, renal and hematological parameters had a satisfactory improvement (Figure 2). On the 14th day of his hospitalization the patient was complaining of shortness of breath. Jugular venous distention was noted.

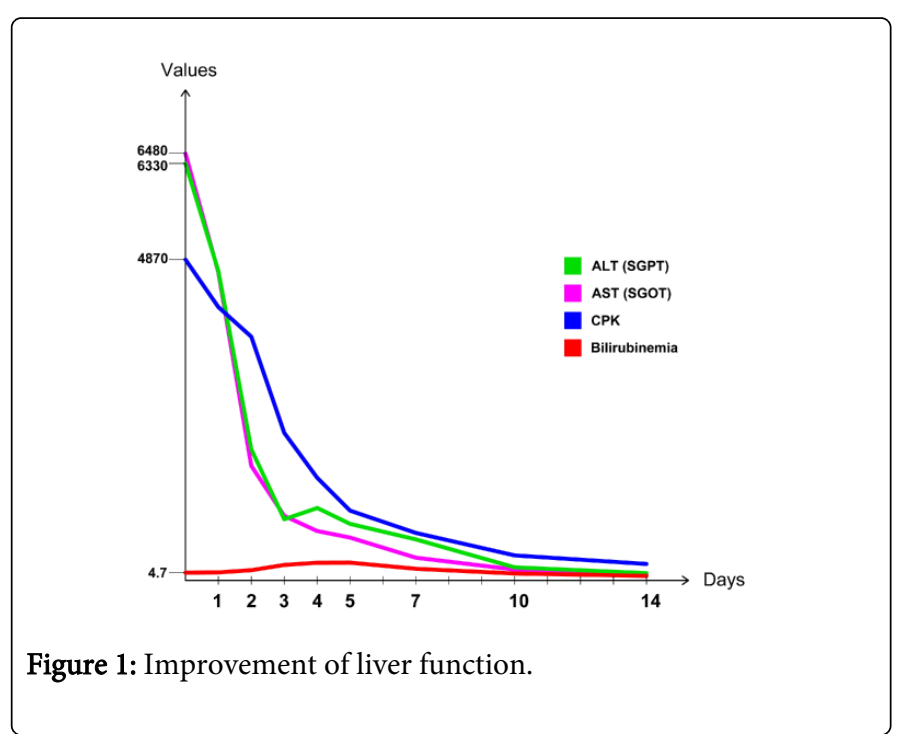

Based on clinical examination, EKG performed and the echocardiography examination the patient was diagnosed with exudative pericarditis. 


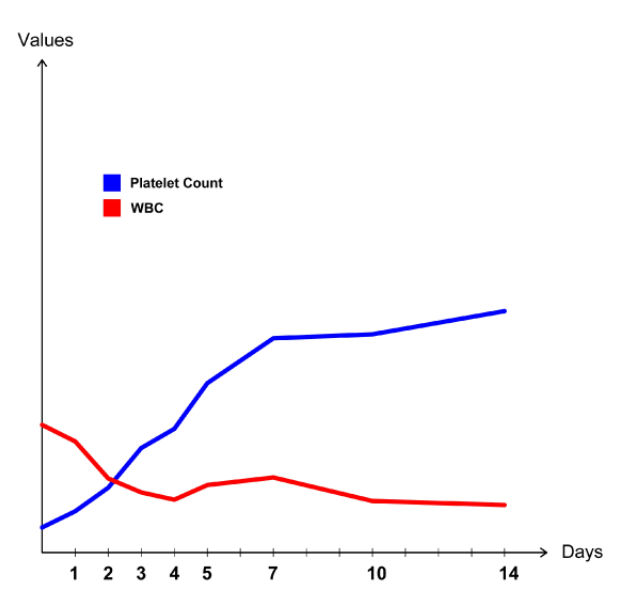

Figure 2: Improvement of platelets counts and WBCc.

Since the amount of pericardial liquid was moderate to severe, one pericardiocentesis was done immediately and the liquid was sent for further examination (Figure 3). The biochemical results of the pericardial effusion were as follows: glucose $114 \mathrm{mg} / \mathrm{dl}, \mathrm{LDH} 194$ $\mathrm{UI} / \mathrm{dl}$, amylase $25 \mathrm{UI} / \mathrm{dl}$, albumin $2.9 \mathrm{mg} / \mathrm{dl}$, cholesterol $144.9 \mathrm{mg} / \mathrm{dl}$, instead of normal value. The cytological examination of the fluid showed RBCs, few mononuclear cells and many mesothelial cells with reactive appearance.

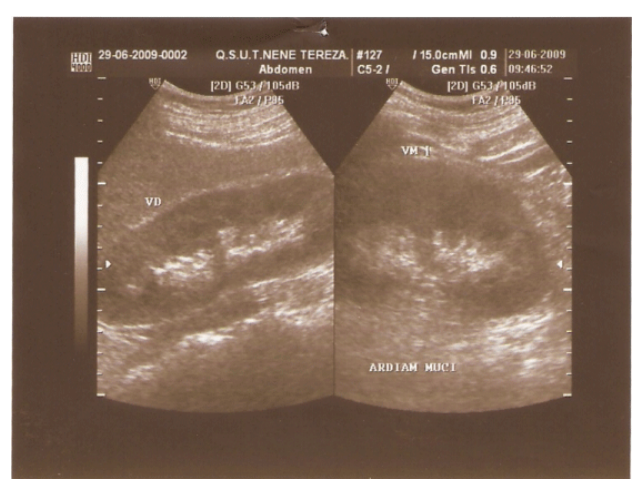

Figure 3: Image of pericarditis.

\section{Discussion}

Leptospirosis is a zoonosis widespread in the world, especially in the tropical countries, which may lead to multiorgan involvement during its course. Wild and domestic animals are the natural reservoirs of the spirochetes, and professional activities may favor the indirect contact with the infectious agent. Human infection results from exposure to infected urine of carrier mammals, either directly or via contamination of soil or water [1-5]. Our patient was exposed to rodents at his workplace and he was served unpacked food which could have been the source of infection. Although denying any direct contacts with rodents he acknowledged that he had seen rodents on several occasions at his workplace. Another very important clue was the fact that the patient was working in a location known for leptospirosis endemicity. Pathogenic leptospires can survive in urine- contaminated water and soil for several weeks, which is an extremely important factor to transmission. The classic clinical presentation of leptospirosis is biphasic, with the acute or septicemic phase lasting about a week, followed by the immune phase, characterized by antibody production. Most of the complications of leptospirosis occur during the second week of the illness. The icteric forms of leptospirosis have a severe clinical presentation and very often are associated with dismal prognosis [1,5]. The term Weil's disease is used to describe severe leptospirosis with evidence of liver and renal impairments [1-10]. The symptoms of our case were fever, headache, myalgia and oligoanuria which were consistent with the literature in patients with leptospirosis [1-4]. Although conjunctival suffusion has been noted as being the most characteristic and diagnostically helpful physical finding of leptospirosis [4]. In our case conjunctival suffusion, rash, clinical presentation, epidemiological data were a god information to suspect leptospirosis. He had acute renal failure and acute hepatitis caused by leptospirosis infection, typically for Weil's disease. Also, it is the first case report with very high level of transaminases from leptospirosis infection, which was complicated with pericarditis. Hepatorenal involvements are seen often in moderate and severe leptospirosis and this has been linked to the basics of the pathophysiology of the disease, damage to the vascular endothelium $[1,5]$. Despite this fact, an increase at this extent of the liver transaminases is rare. A possible explanation to this could be a synergetic effect of the disease itself (vasculitis) with hypoxic state that our patient was in, regarding lung involvement and low blood pressure. The improvement of these components must have contributed to the fast lowering of liver transaminases. Our patient was presented at the first phase a disease as a septic shock stage (leukocytosis, fever, hart rate, blood pressure, thrombocytopenia, hepato-renal-lunch involvement etc). Hypotension and shock occurs in patients with leptospirosis especially during the septicemic phase [5-7]. Patients can develop important hemodynamic abnormalities, secondary to hypovolemia, which is caused by dehydration and direct effects of Leptospira toxins that damages vascular endothelium and increases permeability [3]. This situation: vasculitis, vassal permeability, anuria, and hypoxia are as circles that in the end finish with the cells death. Based on my experience, I think that right here, in this circle is and the key for recover. Firstly to rise blood pressure and then to use diuretics. Based on the serologic and imaging studies that we performed, we didn't find any other explanation to the raise of the transaminases. Furthermore the patient was not an alcohol consumer and the serologies for autoimmune hepatitis were negative.

As we have stressed above, leptospirosis is a systemic disease. The descriptions of cardiac involvement are common, but underreported. Only $10 \%$ of patients are reported to have cardiac involvement but the number could be more. In any case, little is known about the pathophysiology of cardiac involvement in leptospirosis [6]. The most common findings are abnormalities of conduction, for example a relative bradycardia is usually be founded in many patients, although cases of myocarditis can be seen [1,2,6-11]. As with ECG abnormalities, rhythm disturbances associated with leptospirosis usually resolve early in the course of the illness. Endocarditis has been reported as an extremely rare complication in leptospirosis, also [7]. Although leptospirosis induced pericarditis has been reported in several studies, the etiology and prevalence remain unclear. For example in a study of Trivedi et al., $20 \%$ of patients had minimal pericardial effusion with mild pericardial thickening. All these patients had advanced renal failure, suggesting that uremia might have been responsible for the pericarditis and consequent pericardial effusion 
[10]. Because of the high incidence of severe renal disease in these patients, the distinction between uremic pericarditis and that which is the direct result of leptospirosis may be difficult. Studies correlating the clinical and pathologic findings in these patients have not yet been done. The diagnosis has usually been established by the presence of a pericardial friction rub or ECG findings, or both, characteristic of pericarditis [8]. But our patient's clinical course was complicated with percarditis on day 14th of his hospitalization or day 17 th from his symptoms appearance. At this time correlates with the second phase of the disease which is the immune one and the level of renal parameters were almost normal. So pericarditis in our case me be connected with immunity phase than uremic degree. Pulmonary edema occurs in patients with leptospirosis, but could be explained by acute respiratory distress syndrome or volume overload as a result of oliguric renal failure, like our patient was [5]. Regarding to the diagnosis of leptospirosis, it very important for the clinicians that work in endemic areas for this disease to do the serologic testing despite the clinical presentation. In our case we have used ELISA with two different measures, ten days apart from each other. On the first measure the IgM was positive, and on the second measure a significant increase in IgG was noted. We did not have the possibility to do the microscopic agglutination test for leptospirosis, which is a very important test for the diagnosis of the leptospirosis.

The treatment of leptospirosis is multidisciplinary, at first an appreciation of the state that the patient is in, is required. We need to normalize as soon as possible the hemodynamic parameters. By doing so, we prevent or/and ameliorate the renal failure. The antibiotics that are usually used for leptospirosis, are ampicillin or doxycycline, they have the best efficacy and are low cost. In our case we have used ampicillin $6 \mathrm{gr} /$ day; meanwhile we have treated pericarditis with NSAIDs.

\section{Conclusions}

Severe leptospirosis may present a large variety of clinical outlines. Our case was interesting in terms of grave liver damages and pericarditis complication. In general, diagnosis is based on initially upon clinical suspicion, epidemiology, confirmed later by the serology. The involvement of the pericardium as a complication of leptospirosis is not unknown, but they are seldom described by clinicians.

\section{References}

1. Levett PN (2001) Leptospirosis. Clin Meicobiol Rev 14: 296-316.

2. Turhan V, Özmen N, Ulusoy E, Aparci M, Gur M (2008) Cardiac leptospirosis, a case report and review. Anatol J Clin Investig 3: 54-56.

3. Daher EF, Lima RS, Silva Júnior GB, Silva EC, Karbage NN, et al. (2010) Clinical presentation of leptospirosis: a retrospective study of 201 patients in a metropolitan city of Brazil. Braz J Infect Dis 14: 3-10.

4. Mansour-Ghanaei F, Sarshad A, Fallah MS, Pourhabibi A, Pourhabibi K, et al. (2005) Leptospirosis in Guilan, a northern province of Iran: assessment of the clinical presentation of 74 cases. Med Sci Monit 11: CR219-223.

5. Seguro AC, Andrade L (2013) Pathophysiology of leptospirosis. Shock 39 Suppl 1: 17-23.

6. Santos VM, Santos UM1, Gebrin DG1, Santos AM1, Cancado AC1 (2014) Anicteric leptospirosis with pneumonitis, pericarditis and acalculous cholecystitis. Infez Med 22: 236-240.

7. Navinan MR, Rajapakse S (2012) Cardiac involvement in leptospirosis. Trans R Soc Trop Med Hyg 106: 515-520.

8. Dixon AC (1991) The cardiovascular manifestations of leptospirosis. West J Med 154: 331-334.

9. Farkas PS, Knapp AB, Lieberman H, Guttman I, Mayan S, et al. (1981) Markedly elevated creatinine phosphokinase, cotton wool spots, and pericarditis in a patient with leptospirosis. Gastroenterology 80: 587-589.

10. Trivedi SV, Bhattacharya A, Amichandwala K, Jakkamsetti V (2003) Evaluation of cardiovascular status in severe leptospirosis. J Assoc Physicians India 51: 951-953.

11. Erten N, Saka B, Karan MA, Tascioglu C, Polat E et al. (2004) Leptospirosis presented with pericardial effusion, pleurisy and ascites: case report. Ist Tip Fak Mecmuasi 67: 113-115. 